\title{
Performance analysis of free piston Stirling engine based on the phasor notation method
}

\author{
Pengfan Chen ${ }^{*}$, Ying Wang, Wenhao Ding, Yafeng Niu, Zibo Lin, Yingwen Liu \\ Key Laboratory of Thermo-Fluid Science and Engineering of MOE, School of Energy and Power \\ Engineering, Xi' an Jiaotong University, Xi' an, Shaanxi 710049 P R China
}

\begin{abstract}
The free piston Stirling engine (FPSE) is a couple system of dynamics and thermodynamics. Due to the complicated and interactive relationships between the dynamic parameters and thermodynamic parameters, the performance of the FPSE is always difficult to predict and evaluate. The phasor notation method is proposed based on a thermodynamic-dynamic coupled model of a beta-type FPSE in this paper. The output power and efficiency under the different heating temperature and charging pressure are analysed and compared. In addition, based on the Sage numerical model, the influences of heating temperature and charging pressure on the pistons' displacement amplitudes, power work and efficiency are revealed. This study can provide the assistance for the performance analysis, prediction and optimization of the FPSE.
\end{abstract}

\section{Introduction}

The free piston Stirling engine (FPSE) is invented by Beale in $1964^{[1,2]}$, which eliminates the motor as well as the crankshaft. For the features of compactness, long-term life and light mass, it has been applied in various areas such as aerospace technologies, military industry, solar power generations and so on ${ }^{[3]}$. However, such mechanical simplification comes with a price and high costs. Without the connecting rods and crankshafts, the movements of the driving piston and the displacer become less predictable because the pneumatic force they sustain is affected by various factors such as the geometry of the components, charge pressure and spring stiffness. Some unexpected factors could result in substantial deviation of their movement amplitudes and phases, which could lead to a significant decrease in output power and thermal efficiency.

Nevertheless, the temptation of such mechanical simplification is so huge that great efforts has been made to model and predict the movement of the power piston and displacer with various mathematical models. In most basic analysis of FPSE dynamics, the Schmidt isothermal model is adopted to couple the thermodynamics and dynamics of the FPSE ${ }^{[4]}$. Redlich and Berchowitsz applied linear dynamics model to plot a root locus under various parameters and operating conditions ${ }^{[5]}$. Benvenuto and de Monte studied a linear methodology to optimize and evaluate the performance of FPSE dynamics for space applications. The effects of temperature variations of the compression and expansion spaces

* Corresponding author: cpfcast@163.com 
on the spring stiffness were analyzed and the gas spring space were included as linear damping terms ${ }^{[6]}$. Rogdakis presented the matrix model eigenvalues to analysis a stability based on a linear dynamic model ${ }^{[7]}$. Ulusoy applied the nonlinear effects on FPSE using isothermal and non-isothermal modeling, and studied the nonlinear damping term, nonlinear pressure loss ${ }^{[8]}$. In this study, an idealized mathematical model is established and some important parameters are discussed based on this model, which would analyse the coupling dynamic and thermodynamic characteristics of FPSE.

Table1. Explanation of physics notations in figure1

\begin{tabular}{|c|c|}
\hline $\begin{array}{l}\text { Physics } \\
\text { Notation }\end{array}$ & Explanation \\
\hline$m_{d}$ & Total mass of displacer and rod (kg) \\
\hline$m_{p}$ & mass of power piston $(\mathrm{kg})$ \\
\hline$k_{d}$ & Stiffness of spring connects to displacer (N/m) \\
\hline$k_{p}$ & Stiffness of spring connects to power piston (N/m) \\
\hline$c d$ & Damping coefficient of displacer $(\mathrm{N} \cdot \mathrm{s} / \mathrm{m})$ \\
\hline$C p$ & Damping coefficient of power piston $(\mathrm{N} \cdot \mathrm{s} / \mathrm{m})$ \\
\hline$C_{p}$ & Equivalent damping coefficient $(\mathrm{N} \cdot \mathrm{s} / \mathrm{m})$ \\
\hline$A_{1}$ & Cross-sectional area of displacer $\left(\mathrm{m}^{2}\right)$ \\
\hline$A_{2}$ & Cross-sectional area of power piston $\left(\mathrm{m}^{2}\right)$ \\
\hline$p$ & Instantaneous pressure $(\mathrm{Pa})$ \\
\hline$|p|$ & Amplitude of pressure $(\mathrm{Pa})$ \\
\hline$p_{0}$ & Charge pressure $(\mathrm{Pa})$ \\
\hline$p_{m}$ & Average pressure $(\mathrm{Pa})$ \\
\hline$t$ & Time (s) \\
\hline$T_{H}$ & Heating temperature $(\mathrm{Pa})$ \\
\hline$T_{L}$ & Cooling temperature $(\mathrm{Pa})$ \\
\hline$V_{H}$ & Instantaneous volume of expansion space $\left(\mathrm{m}^{3}\right)$ \\
\hline$V_{L}$ & Instantaneous volume of compression space $\left(\mathrm{m}^{3}\right)$ \\
\hline$V_{R}$ & Void volume of regenerator $\left(\mathrm{m}^{3}\right)$ \\
\hline$V_{H 0}$ & Volume of expansion space at equilibrium state $\left(\mathrm{m}^{3}\right)$ \\
\hline$V_{L 0}$ & $\begin{array}{l}\text { Volume of compression space at equilibrium state } \\
\qquad\left(\mathrm{m}^{3}\right)\end{array}$ \\
\hline$x_{d}$ & Instantaneous displacement of displacer $\left(\mathrm{m}^{3}\right)$ \\
\hline$x_{p}$ & Instantaneous displacement of power piston $\left(\mathrm{m}^{3}\right)$ \\
\hline$\left|x_{d}\right|$ & Amplitude of displacer's displacement (m) \\
\hline$\left|x_{p}\right|$ & Amplitude of power piston's displacement (m) \\
\hline$Q_{H}$ & Absorbed heat $(\mathrm{J})$ \\
\hline$Q_{L}$ & Rejected heat $(\mathrm{J})$ \\
\hline$W_{c d}$ & Work consumed by displacer's damping $(\mathrm{J})$ \\
\hline$W_{c p}$ & Work consumed by power piston's damping $(\mathrm{J})$ \\
\hline$W_{\text {output }}$ & Output power $(\mathrm{J})$ \\
\hline$\omega$ & Angular frequency $(\mathrm{J})$ \\
\hline$\varphi_{d}$ & $\begin{array}{l}\text { Phase difference between pressure and displacer's } \\
\text { displacement }\end{array}$ \\
\hline$\varphi_{p}$ & $\begin{array}{c}\text { Phase difference between pressure and power piston's } \\
\text { displacement }\end{array}$ \\
\hline$\eta$ & efficiency \\
\hline
\end{tabular}

\section{The mathematical model}

\subsection{A subsection Object and assumptions}


The mathematical model is established upon a drawing of a $\beta$ type free-piston Stirling engine which is shown in Figure 1. This Stirling engine is mainly comprised of two chambers, two pistons and three heat exchangers. The two chambers are expansion space and compression space, the two pistons are displacer and power piston, and the three heat exchangers are the heater, cooler and regenerator. The displacer is connected to the blade springs with a rod extruded into the bounce space, which is separated with power piston by an ideal clearance seal. The spring forces are exerting on the displacer as well as the power piston to adjust their motion. $A_{1}$ is greater than $A_{2}$ due to the existence of the rod. Detailed explanations of the physics notations in Fig. 1 have been listed in Table1.

To establish the model, some assumptions are made as follows.

The instantaneous pressure of working fluid inside each components are always equal and uniform;

The temperature of working fluid inside the expansion space, the compression space and regenerator are equal to $T_{\mathrm{H}}, T_{\mathrm{L}}$ and $\left(T_{\mathrm{H}}+T_{\mathrm{L}}\right) / \ln \left(T_{\mathrm{H}} / T_{\mathrm{L}}\right)$, respectively;

-Neither leakage nor friction occurs in the clearance seals;

-During the operation, the instantaneous pressure in expansion space and compression space are equal and the pressure inside the bounce space remains constant and equals to pm; - The displacer and power piston execute simple harmonic motion, while the pressure oscillates in a simple harmonic manner, the phase angle of pressure is set to be zero;

- The working fluid is ideal gas;

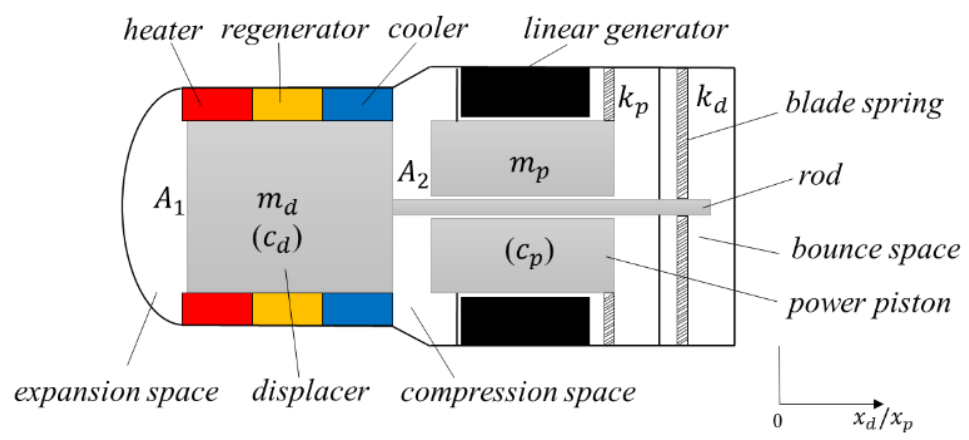

Fig. 1. A drawing of the FPSG.

\subsection{The dynamic analysis of displacer and power piston}

The Newton's Second law is applied in analyzing the dynamic characteristics of displacer and power piston, the forces that subjected to the displacer includes the gas force, spring force and damping force, which can be presented as eq(1),

$$
p A_{1}-p A_{2}-p_{m}\left(A_{1}-A_{2}\right)-k_{d} x_{d}-c_{d} \frac{d x_{d}}{d t}=m_{d} \frac{d^{2} x_{d}}{d t^{2}}
$$

where $p, p_{m}$, and $x_{d}$ represent the instantaneous pressure, the average pressure and the displacement of the displacer, respectively, which can be represented as follows based on harmonic assumptions, so the phasor form of eq(1) can be reduced as eq(4), where the boldface physics notations represents the phasors of $p, x_{d}$ and $x_{p}$. The phasor diagram is represented in Fig.2. 


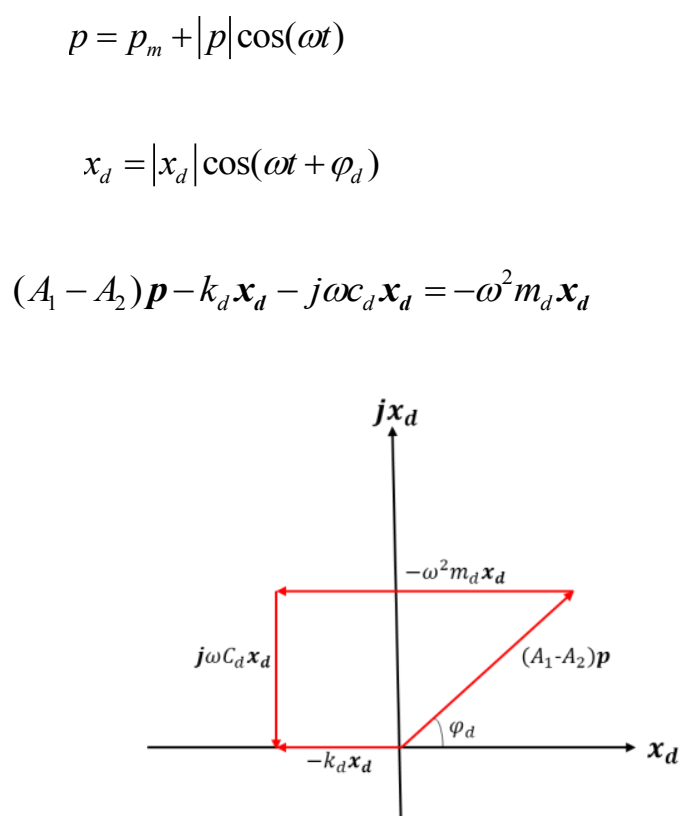

Fig. 2. Phasor diagram of displacer.

Similarly, the identical derivation process can be applied to the power piston's dynamic analysis. However, the power piston is also subjected to the reversed magnetic force produced by the linear alternator that can be calculated by eq(6), where $\boldsymbol{F}_{\boldsymbol{B}}$ means the reversed magnetic force, $B, L$ and $R$ means the magnetic intensity, the loop length and its resistance, repectively.

$$
\begin{gathered}
A_{2} \boldsymbol{p}-k_{p} \boldsymbol{x}_{p}-\boldsymbol{F}_{\boldsymbol{B}}-j \omega c_{p} \boldsymbol{x}_{p}=-\omega^{2} m_{p} \boldsymbol{x}_{p} \\
\boldsymbol{F}_{\boldsymbol{B}}=\left(\frac{B^{2} L^{2}}{R}\right) \frac{d \boldsymbol{x}_{p}}{d t}
\end{gathered}
$$

According to eq(6), the magnetic force is proportional to the displacer's velocity, which can be merged with damping force, so the dynamic equation of power piston can be given as follow, the $c_{p}$ ' means the equivalent damping coefficient, and phasor diagram of power piston is represented in figure 3. Something should be noted is that the magnetic force subjects to the power piston in this study, it can also subject to displacer, which is determined by the structure of FPSG system.

$$
A_{2} \boldsymbol{p}-k_{p} \boldsymbol{x}_{p}-j \omega c_{p} \boldsymbol{x}_{p}=-\omega^{2} m_{p} \boldsymbol{x}_{p}
$$




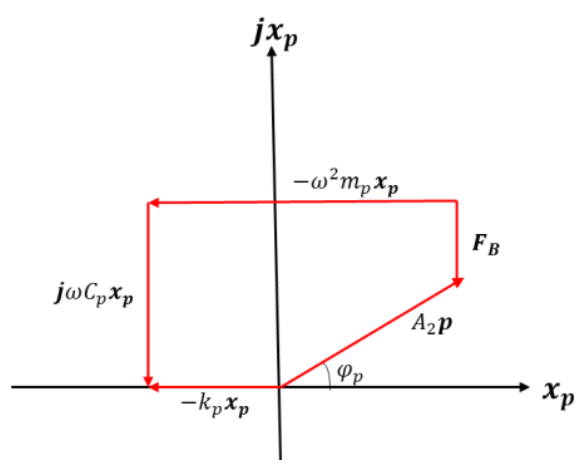

Fig.3. Phasor diagram of power piston.

\subsection{The mass conservation analysis of working fluid}

FPSE is a closed thermal system with the high frequency oscillating operating conditions, the total mass of working fluid is conservative. It means the sum of the gas mass in the expansion space, compression space and regenerator when the system is working remains a constant, which is equal to the initial charged gas mass, and is also equal to the total gas mass when the system is terminated. $V_{H}, V_{L}$ represent the instantaneous volume of expansion space and compression space. $V_{H O}, V_{L O}$ represent the volume of expansion space and compression space at equilibrium state, respectively.

$$
m=\frac{p}{R_{g}}\left(\frac{V_{H}}{T_{H}}+\frac{2 V_{R}}{T_{H}+T_{L}}+\frac{V_{L}}{T_{L}}\right)=\frac{p_{0}}{R_{g}}\left(\frac{V_{H 0}+V_{R}+V_{L 0}}{T_{L}}\right)=\frac{p_{m}}{R_{g}}\left(\frac{V_{H 0}}{T_{H}}+\frac{2 V_{R}}{T_{H}+T_{L}}+\frac{V_{L 0}}{T_{L}}\right)
$$

After excluding all the second-order terms and applying phasor notation, eq(9) can be given as follow,

$$
B_{1} \boldsymbol{p}+B_{2} \boldsymbol{x}_{\boldsymbol{d}}+B_{3} \boldsymbol{x}_{\boldsymbol{p}}=\mathbf{0}
$$

and three parameters $B_{1}, B_{2}, B_{3}$ are defined,

$$
\begin{array}{r}
B_{1}=\frac{V_{H 0}}{T_{H}}+\frac{2 V_{R}}{T_{H}+T_{L}}+\frac{V_{L 0}}{T_{L}} \\
B_{2}=p_{m}\left(\frac{A_{1}}{T_{H}}-\frac{A_{2}}{T_{L}}\right) \\
B_{3}=p_{m}\left(-\frac{A_{2}}{T_{L}}\right)
\end{array}
$$


After the analysis of dynamics and mass conservation of working fluid, the basis equations of FPSE are derived which comprised of $\mathrm{Eq}(4), \mathrm{Eq}(7)$ and $\mathrm{Eq}(9)$. They give a complete description of the dynamic characteristics of displacer and power piston. Fig.4 presents the phasor diagram of $\boldsymbol{x}_{\boldsymbol{d}}, \boldsymbol{x}_{\boldsymbol{p}}$ and $\boldsymbol{p}$.

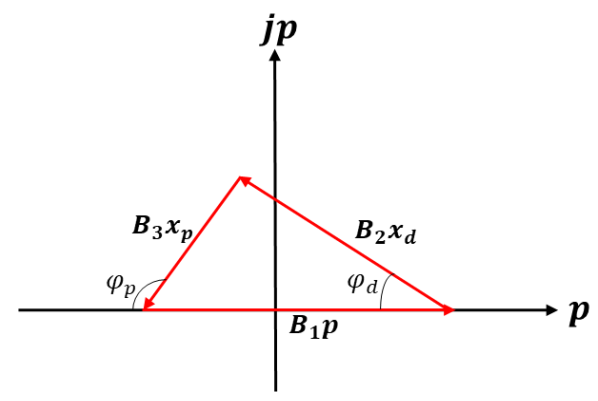

Fig.4. Phasor diagram of FPSG.

\subsection{Power and efficiency}

\subsubsection{Absorbed heat and rejected heat}

The heating capacity at expansion space is derived based on variable mass system thermodynamics, the expression can be written as eq(13),

$$
\delta Q=d U-h d m+p d V
$$

so the heating capacity is given as follow,

$$
\left\langle Q_{H}\right\rangle=\frac{\omega}{2 \pi} \int_{0}^{\frac{2 \pi}{\omega}}\left[p \frac{d V_{H}}{d t}+\left(c_{v}-c_{p}\right) T_{H} \frac{d m_{H}}{d t}\right] d t=-\frac{A_{1}}{2} \omega|p|\left|x_{d}\right| \sin \varphi_{d}
$$

similarly, the cooling capacity at compression space can be calculated and given,

$$
\left\langle Q_{L}\right\rangle=\frac{\omega}{2 \pi} \int_{0}^{\frac{2 \pi}{\omega}}\left[p \frac{d V_{L}}{d t}+\left(c_{v}-c_{p}\right) T_{L} \frac{d m_{L}}{d t}\right] d t=\frac{A_{2}}{2} \omega|p|\left|x_{d}\right| \sin \varphi_{d}+\frac{A_{2}}{2} \omega|p|\left|x_{p}\right| \sin \varphi_{p}
$$

\subsubsection{Damping dissipation work}

During the operation, the expansion space transforms the heat into acoustic work, which drives the power piston and linear alternator to produce electrical work. However, due to the damping of displacer and power piston, a part of work will be consumed by the damping forces which can be calculated by eq(16) and eq(17),

$$
\begin{aligned}
& \left\langle W_{c_{d}}\right\rangle=\frac{\omega}{2 \pi} \int_{0}^{\frac{2 \pi}{\omega}} c\left(\frac{d x_{d}}{d t}\right)^{2} d t=\frac{c_{d} \omega^{2}\left|x_{d}\right|^{2}}{2} \\
& \left\langle W_{c_{p}}\right\rangle=\frac{\omega}{2 \pi} \int_{0}^{\frac{2 \pi}{\omega}} c_{p}^{\prime}\left(\frac{d x_{p}}{d t}\right)^{2} d t=\frac{c_{p}^{\prime} \omega^{2}\left|x_{p}\right|^{2}}{2}
\end{aligned}
$$


Because the mathematical model is under the isothermal assumptions, the heat absorbed by expansion space transforms into the heat rejected by heat sink, damping dissipation work and output power, The output power produced by FPSG during a cycle can be derived based on law of sines and presented as eq(18),

$$
\left\langle W_{\text {output }}\right\rangle=\left|\left\langle Q_{H}\right\rangle\right|-\left|\left\langle Q_{L}\right\rangle\right|-\left|\left\langle W_{c_{d}}\right\rangle\right|-\left|\left\langle W_{c_{p}^{\prime}}\right\rangle\right|=\frac{1}{2} A_{2} \omega|p|\left|x_{p}\right| \sin \varphi_{p}
$$

therefore, the thermal efficiency of FPSE system is given as follows,

$$
\eta=\frac{\left\langle W_{\text {output }}\right\rangle}{\left\langle Q_{H}\right\rangle}=\frac{A_{2}}{A_{1}}-\frac{T_{L}}{T_{H}}<\eta_{\text {Carnot }}
$$

due to $A_{2}$ is less than $A_{1}$, so the thermal efficiency is less the Carnot efficiency. Eq(19) reveals that because of the necessary damping forces of displacer and power piston, the thermal efficiency of FPSE is actually the upper limit of the FPSE's efficiency. Therefore, FPSE is inherently of lower efficiency. Additionally, the cross-sectional area difference between displacer and power piston is necessary to the production of power.

\section{Discussion}

Since the idealized mathematical model is established upon various assumptions, it is necessary to compare this model with a more practical numerical model which is established with a commercial software Sage. Fig.5 to Fig.8 presents the displacement amplitudes, power work and efficiency under different heating temperature and charge pressure of thermodynamic-dynamic mathematical model.

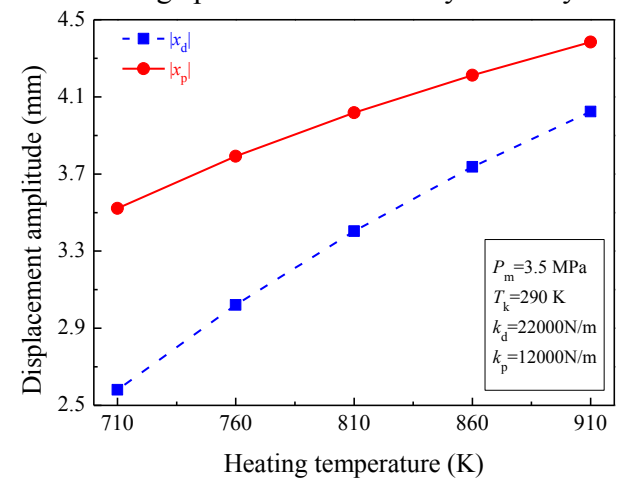

Fig.5. Displacement amplitude versus heating temperature.

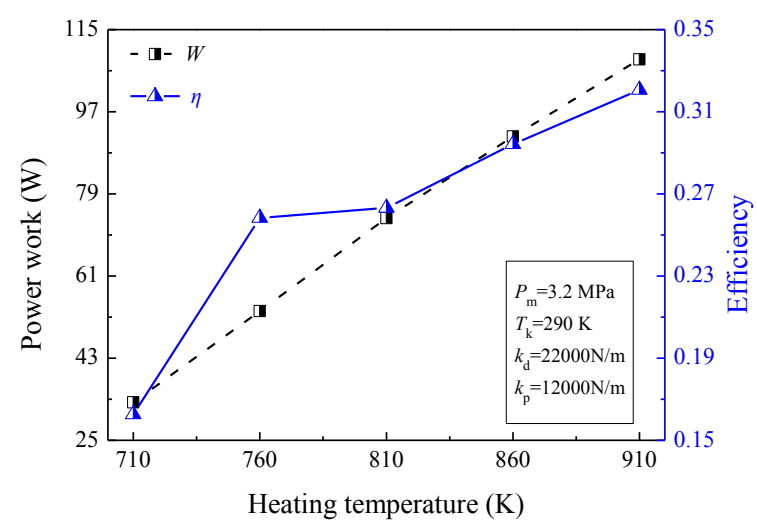

Fig.6. Power work and efficiency versus heating temperature. 


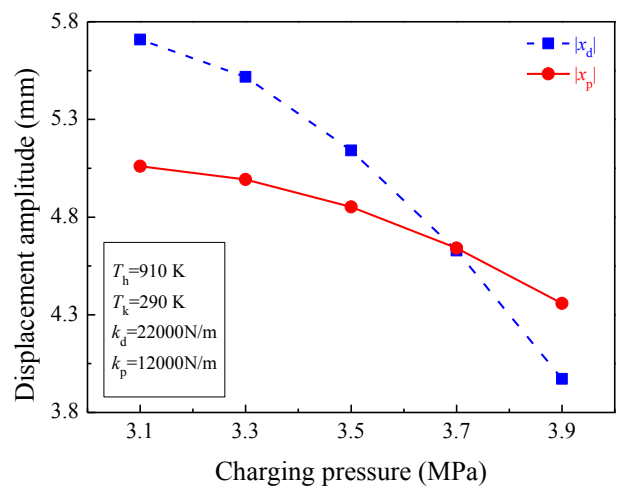

Fig.7. Displacement amplitude versus charging pressure.

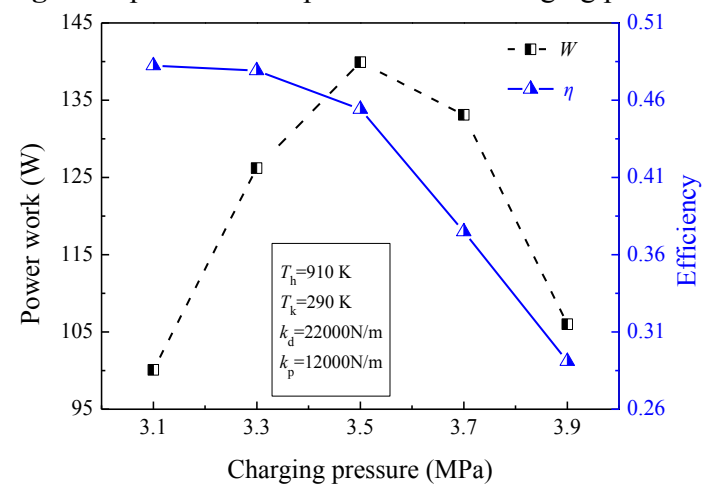

Fig.8. Power and efficiency versus charging pressure.

\section{Conclusion}

This paper has established an idealized mathematical model based on a series of assumptions. The expression of output power, damping dissipation work and thermal efficiency as well as basis dynamic equations of FPSE have been derived. In summary, following conclusions can be achieved. - The damping forces of displacer and power piston are necessary for the production of output work, but they also consume a part of absorbed heat, which cannot be avoided and make FPSE inherently less efficient;

-The the cross-sectional area difference between displacer and power piston is also necessary to the production of power.

Due to the viscous flow resistance and the incomplete heat transfer in the regenerator, the

discrepancy are caused between the results of thermodynamic-dynamic coupled model and

Sage model.

In general, Sage numerical model can provide rather precise results applicable to practical designs and manufactures. For the mathematical model, although based upon more simplifying assumptions and less accurate, it provide formulae which can reveal the nature of FPSE and help us understand the mechanism behind the numerical results. So, the future work should be devoted to establishing an optimal design method based on the idealized model, which would work as a preliminary optimization before further numerical simulation.

\section{References}

1. Beale W. Stirling cycle type thermal device. US Patent 3552120, 1971. 
2. Beale W. Free-piston Stirling engines-Some model tests and simulations. SAE Technical Paper 690230, 1969.

3. Edward J L, Paul K J. Stirling System Modeling for Space Nuclear Power Systems. NASA/CR-2008-215146:1-14.

4. Urieli I, and Berchowitz D M. Stirling Cycle Engine Analysis, Adam Hilger, Bristol, 1984:51-69.

5. Redlich R W, Berchowitz D M. Linear Dynamics of Free-Piston Stirling Engines. Proc. Inst. Mech. Eng., Part C, 1985, 199(31):203-213.

6. Benvenuto G, de Monte F. Analysis of Free-Piston Stirling Engines/Linear Alternator Systems Part 1: Theory. Journal of Propulsion and Power, 1995, 11: 1036-1046.

7. Rogdakis E D, Bormpilas N A, Koniakos, I K.A Thermodynamics Study for the Optimization of Stable Operation of Free Piston Stirling Engines. Energy Conversion and Management, 2004, 45, (4):575 593.

8. Ulusoy, N. Dynamic Analysis of Free Piston Stirling Engines. Ph.D. thesis, Department of Mechanical and Aerospace Engineering, Case Western Reserve University, 1994. 